\title{
Biological pretreatment of lignocellulosic materials with white rot fungi for enzymatic hydrolysis
}

\author{
Rasool Ghasemzadeh* ${ }^{1}$, Ali Arasteh nodeh ${ }^{1}$
}

\begin{abstract}
The effects of fungal pretreatment on the rapeseed straw, was evaluated after solid state cultivation of white rot fungi Phanerochaete Chrysosporium. P. Chrysosporium degraded the lignin during the pretreatment, and the pretreated straw showed increases in enzymatic hydrolysis ratios (3-fold after 15- day pretreatment).The samples were identified by FTIR and XRD. Xray analysis showed that pretreated samples had a higher crystallinity than untreated samples $(39.47 \%$ for a pretreated sample compared to $33.17 \%$ at untreated) and FTIR spectroscopy demonstrated that the content of lignocellulose decreased during the biological pretreatment process. Moreover, the biological pretreatment slowed down the decline in hydrolysis rate during enzymatic hydrolysis.
\end{abstract}

Keyword: Rapeseed straw, Phanerochaete Chrysosporium, Fungal pretreatment, Enzymatic hydrolysis, Reducing sugar

\section{Introduction}

The third oil used in the world is rapeseed (Brassica napus) oil. After oil extraction, the residual dross of rapeseed can be used for animal feed production due to its protein content. In recent years, a significant increase has been seen in using rapeseed oil to produce biodiesel. The area under rapeseed cultivation in the world was over 36 million hectares in 2013[1] and Iran's share was 170000 hectares. After harvesting and separating rapeseed seeds, the agricultural residues are usually burned. Considering its lignocellulosic nature, rapeseed straw can be used fuel ethanol production by a biochemical process. This process includes pretreatment, enzymatic hydrolysis, and fermentation. Enzymatic hydrolysis is an important step of changing lignocellulosic materials into biofuel.

The resistant structure of lignin causes some limitations on decomposing the lignocellulosic materials and changing them into ethanol [2,3]. Developing the existing pretreatment methods has been mainly based on physicchemical technologies such as using hot water[4], diluted and concentrated acids[5-7], and alkaline [8, 9]. But these processes usually require high temperature and operating pressure. Generally, these pretreatment have major disadvantages: (a) the need to the equipment resistant to corrosion and pressure (b) the production of environmentally high-risk effluent by most of these processes and (c) high energy consumption[10].

1.Department of Chemical Engineering, Quchan Branch, Islamic Azad University, Quchan, Iran
Biological pretreatments by microorganisms and their enzyme systems can degrade lignin and hemicellulose existing in the lignocellulosic materials using low levels of energy and mild environmental conditions [11, 12]. White rot fungi are a group of basidiomycetes and have a unique ability to degrade the structure of lignin and carbohydrates $[13,14]$. These fungi can decompose lignocellulosic materials thanks to the production of two enzymatic systems: (a) hydrolytic system, which produce cellulases and hemicellulases that degrade polysaccharides and (b) an oxidative lignolytic system which degrade lignin and opens the phenyl rings. Lignin proxidase (Lip), manganese proxidase (Mnp) and laccase are the most major of these enzymes $[3,11]$. White rot fungi can produce some or all of these enzymes. P.Chrysosporium is one of the most important candidates and researchers have done different pretreatments by using it $[2,3,15]$. The main purpose of the present study was the solid-state fermentation of rapeseed straw by P.Chrysosporium without using any nutrients. The biodegradation patterns of the pretreated straw were also evaluated by chemical component losses, Fourier transform infrared (FTIR) and X-ray diffraction analysis.

\section{Materials and Methods \\ A. Biomass and microorganism}

The rapeseed straw was supplied from rapeseed farms in Quchan, Khorasan Razavi Province, Iran in the crop year 2011. To remove the soil particles and unwanted materials, the rapeseed straw was washed with water and dried in the laboratory environment for one week. Then, it was dried using an oven at $60^{\circ} \mathrm{C}$ for 24 hours to reach a constant weight. The dried rapeseed straw was grounded, passed through 18-mesh sieve, packed in nylon containers for further use, and stored at room temperature.

The lyophilized P.Chrysosporium (ATCC 24725) was purchased from Iran's regional center for collection of industrial fungi and bacteria. The organism was propagated on potato dextrose agar (PDA) plates at $30^{\circ} \mathrm{C}$ for one week; the spores were kept in dark at $4^{\circ} \mathrm{C}$ until use. Spore suspensions were prepared by washing the agar surface with distilled water, and were diluted so that the absorbance at $650 \mathrm{~nm}$ was 0.5 , in a $1 \mathrm{~cm}$ path-length cuvette according to Sedighi et al. [16]. There were $2 \times 10^{6}$ spores per milliliter of the suspension solution. To ensure the appropriate function of the fungus, a new culture medium was prepared every two months.

\section{B. Biological pretreatment with P. Chrysosporium}

$5 \mathrm{~g}$ of the rapeseed straw was put into a capped $250 \mathrm{ml}$ jar and were sterilized in the autoclave at $121^{\circ} \mathrm{C}$ for $15 \mathrm{~min}$ and allowed to cool to room temperature. Of the spore suspension, $2.5 \mathrm{ml}$ was added to the jar, and moisture of the medium was increased to $80 \%$ (w water)/(w total) using 
sterile distilled water. The cultures were capped and incubated at $37^{\circ} \mathrm{C}$ for 5,10 and 15 days. All the cultures were grown in triplicate. In all cases, the rapeseed straw treated in the same conditions without fungal inoculation was used as the control.

\section{Enzymatic hydrolysis}

Enzymatic hydrolysis was carried out in $250 \mathrm{ml}$ Erlenmeyer flask with $1 \mathrm{~g}$ the pretreated sample and $100 \mathrm{ml}$ of $0.05 \mathrm{M}$ sodium citrate buffer. A certain amount of cellulase (10 FPU/g) was added to each of the flask, and the reaction mixtures were incubated in the shaker incubator at $50^{\circ} \mathrm{C}$ and $150 \mathrm{rpm}$ for maximum 56 hours. The cellulase was obtained from Sigma. Each time point was analyzed for reducing sugar in triplicate and an average value was reported.

\section{Determination of reducing sugar}

Total reducing sugar was determined by the 3,5dinitrosalicylic acid (DNS) method using glucose as the standard [17]. $0.1 \mathrm{ml}$ of the enzymatic hydrolysis solution and $0.9 \mathrm{ml}$ of distilled water were poured into the test tube, and then, $3 \mathrm{ml}$ of DNS solution was added to the tube. The mixture was placed in hot water bath for $5 \mathrm{~min}$ and cooled down to the room temperature. Then, $7 \mathrm{ml}$ of distilled water was added to the tube, and the absorption occurred at wavelength of $540 \mathrm{~nm}$. The absorbance readings were then converted into equivalent sugar concentration $(\mathrm{mg} / \mathrm{ml})$ using a standard glucose curve. The hydrolysis ratio was calculated using the following equation:

Hydrolysis ratio $(\%)=\frac{\text { amount of reducing sugar produced }+0.9}{\text { amount of cellulose }+ \text { amount of femicellulose }}+100$

\section{E. Chemical analysis of rapeseed straw}

Rapeseed straw was dried at $60{ }^{\circ} \mathrm{C}$ to reach a constant weight. Neutral detergent fiber (NDF), acid detergent fiber (ADF), and acid detergent lignin (ADL) were determined according to procedure of Van Soest [18]. The amount of hemicelluloses, cellulose and klason lignin were calculated by the difference between NDF and ADF content, ADF and ADL content, ADL and ash content, respectively. The detail process was described as follows:

About 1 gr of dried rapeseed straw and $100 \mathrm{ml}$ of neutral detergent solution with sodium lauryl sulfate (SDS) and disodium ethylene diamine tetra-acetate (EDTA) were added into a flask for the determination of NDF. The obtained mixture was heated so that it reached the boiling point within 5-10 min and boiled for one hour. Then the hot mixture was filtered, the residue were washed with a minimum of $500 \mathrm{ml}$ of hot distilled water and $10 \mathrm{ml}$ of acetone and dried at $105{ }^{\circ} \mathrm{C}$ to reach a constant weight. The amount of NDF was determined by the following relation:

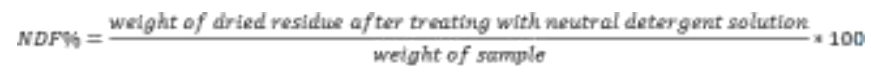

Acid detergent solution and cetyl tri-methyl ammonium bromide (CTAB) and $0.5 \mathrm{M} \mathrm{H} 2 \mathrm{SO} 4$ were used to for the determination of ADF. The method was similar to the determination of NDF.

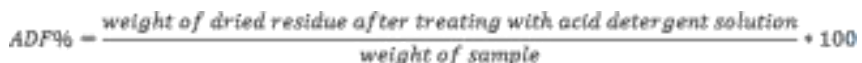

To determination of ADL, the solid material obtained from ADF was digested with $72 \% \mathrm{H}_{2} \mathrm{SO}_{4}$ for 3 hours and then filtered. The residue was completely washed with hot distilled water until acid free to $\mathrm{pH}$ paper. The residue was dried at $105^{\circ} \mathrm{C}$ to reach a constant weight.

$A D L \%=\frac{\text { weight of dried residue af ter treating with } 72 \% \text { sulphoric acid }}{\text { weight of sowpls }}=100$

The ash was determined as the residue after treatment in the muffle at $600{ }^{\circ} \mathrm{C}$ for 24 hours.

$$
\text { Ashor }=\frac{\text { weight of ash }}{\text { weight of sample }} * 100
$$

\section{F. X-ray diffraction analysis}

The crystallinity index (CrI) of untreated and treated rapeseed straw by P.Chrysosporium was collected by X-ray diffractometer in a BRUKER (Germany). All samples were scanned in the range of $2 \theta=0-40^{\circ}$ at the speed of $\left(1^{\circ}\right) / \mathrm{min}$ at $40 \mathrm{KV}$ and $40 \mathrm{~mA}$. The radiation used was $\mathrm{Cu}(1.54 \AA)$. The crystallinity index $(\mathrm{CrI})$ was calculated using the following equation:

$$
\text { Crystallinity index }(\mathrm{Cr} I) \%=\frac{I_{002}-I_{m}}{I_{002}} * 100
$$

Where $\mathrm{I}_{002}$ was the maximum intensity of peaks at $2 \theta$ between $22^{\circ}$ and $23^{\circ}$, and $\mathrm{I}_{\mathrm{am}}$ was the minimum intensity of peaks in $2 \theta$ between $18^{\circ}$ and $19^{\circ}$ [19].

\section{G. Fourier transform infrared spectroscopy (FTIR) analysis}

The FTIR spectra were obtained by direct transmittance using the KBr pellet technique via a Perkin Elmer 100 FTIR spectrometer. All of the spectra $(4000-400 \mathrm{~cm}-1)$ were measured at a resolution of $4 \mathrm{~cm}-1$ and 64 scans per sample.

\section{H. Data treatment}

Equation 1, an empirical model[20]was used for data treatment of enzymatic hydrolysis.

$$
X=\frac{1}{k} \ln \left(1+V_{0} k t\right)
$$

Where: $\mathrm{X}=$ Hydrolysis ratio $(\%), \mathrm{V}_{0}=$ Initial hydrolysis rate $(\% / \mathrm{h}), \mathrm{t}=$ Hydrolysis time, $\mathrm{k}=$ Rate retardation constant. According to Eq. (1), initial hydrolysis rate $\left(\mathrm{V}_{0}\right)$ and rate retardation constant $(\mathrm{k})$ were determined by regression analysis of the experimental results. Data fit was performed by software MATLAB R2013a.

\section{Results and Discussion}

\section{A. The effects of biological pretreatment on chemical composition}

Lignin is an important compound in plant cell walls that limits chemical and biological decomposition, also enzymatic hydrolysis. The reduction of lignin content causes the crystalline structure of cellulose to be exposed and 
facilitates substrate access by hydrolytic enzymes[12]. The effect of biological pretreatment on the rapeseed straw after cultivation with P.Chrysosporium is shown in Table 1. As it is seen, all of the components have decreased with increasing time. In this study, the compounds of the used rapeseed straw include lignin $23.9 \%$, cellulose $35.08 \%$, and hemicellulose $33.83 \%$.

Table 1. Percent losses of different components of the rapeseed straw pretreated by $\mathrm{P}$. Chrysosporium for 5, 10 and 15 days.*

\begin{tabular}{ccccc}
\hline $\begin{array}{l}\text { Pretreatment } \\
\text { Time(day) }\end{array}$ & $\begin{array}{c}\text { Selectivity } \\
\text { value }\end{array}$ & \multicolumn{3}{c}{ Component loss (\%) } \\
\cline { 3 - 5 } & & Lignin & Cellulose & Hemicelluloses \\
\hline 5 & 1.17 & $1.08 \pm 0.32$ & $0.92 \pm 0.72$ & $2.63 \pm 0.22$ \\
10 & 1.47 & $4.36 \pm 0.71$ & $2.94 \pm 0.38$ & $6.44 \pm 0.34$ \\
15 & 1.83 & $6.18 \pm 0.56$ & $3.37 \pm 0.41$ & $7.27 \pm 0.53$ \\
\end{tabular}

*Results are mean of three replicates \pm standard deviation.

The largest amount of lignin degradation was observed on the 15 th days $(6.18 \%)$. This level of lignin removal can be attributed to maximum of lignolytic enzymes production at 15 th days[21]. These results correspond to the reports of other researchers who have studied on biological pretreatment of lignocellulosic materials by white rot fungi [22]. The ratio of lignin degradation to cellulose reduction, selectivity value, can be considered as a factor for delignification efficiency. Higher selectivity means better prospects for preferential delignification and its low level means high removal of cellulose during pretreatment[14]. Selectivity value was used to evaluate the selective lignindegrading ability. As it is shown in Table 1, the selectivity values increased with increasing pretreatment time so that it reaches its largest amount on the 15th day (1.83). Although in some reports it is indicated that the selectivity values decreased with increasing pretreatment time. In other hand, the selectivity turned into a non-selective degradation with increasing pretreatment time $[11,14]$. This subject was not investigated in the present study.

\section{B. FTIR analysis}

FTIR analysis was used to characterize changes in lignocellulosic materials during chemical and biological pretreatments. FTIR spectroscopy of pretreated rapeseed straw (15th day) and untreated straw (0th day) is shown in Figure1. A very strong hydrogen bonded $(\mathrm{O}-\mathrm{H})$ stretching absorption is seen at around $3420 \mathrm{~cm}^{-1}$, while bands at 2920 and $2850 \mathrm{~cm}^{-1}$ represent $\mathrm{C}-\mathrm{H}$ anti-symmetric and symmetric stretching, respectively. Also, the existing peaks of $1800-$ $700 \mathrm{~cm}^{-1}$ represent the following bonds: $1640 \mathrm{~cm}^{-1}$ for absorbed $\mathrm{O}-\mathrm{H}$ and conjugated $\mathrm{C}-\mathrm{O} ; 1440 \mathrm{~cm}^{-1}$ for destroyed $\mathrm{C}-\mathrm{H}$ in lignin; $1380 \mathrm{~cm}^{-1}$ for $\mathrm{C}-\mathrm{H}$ deformation in cellulose and hemicellulose; the peaks between $1200 \mathrm{~cm}^{-1}$ and $1000 \mathrm{~cm}^{-1}$ represent $\mathrm{C}-\mathrm{O}$ stretching and the deformation cellulose, lignin, and residual hemicellulose bonds; $898 \mathrm{~cm}^{-}$ ${ }^{1}$ for C-H deformation in cellulose[14, 23].

There are many similarities between FTIR spectra of pretreated rapeseed straw by P.Chrysosporium (15th day) and untreated rapeseed straw (0th day), indicating selective removal of carbohydrate components. The intensity of absorption has considerably decreased with increasing pretreatment time, indicating the solubilisation of the constituents of lignocelluloses fraction. Elimination or reduction of absorption intensity at the peaks of $1060 \mathrm{~cm}-1$, $1160 \mathrm{~cm}-1$, and $898 \mathrm{~cm}-1$ with increasing pretreatment time, are indicating that the destruction of lignocellulosic structure is possible with an increase in time. According to FTIR spectra, it suggests that the incubation period allowed in fungal treatment should be increased to facilitate solubility of lignocellulose and further breakdown to occur.

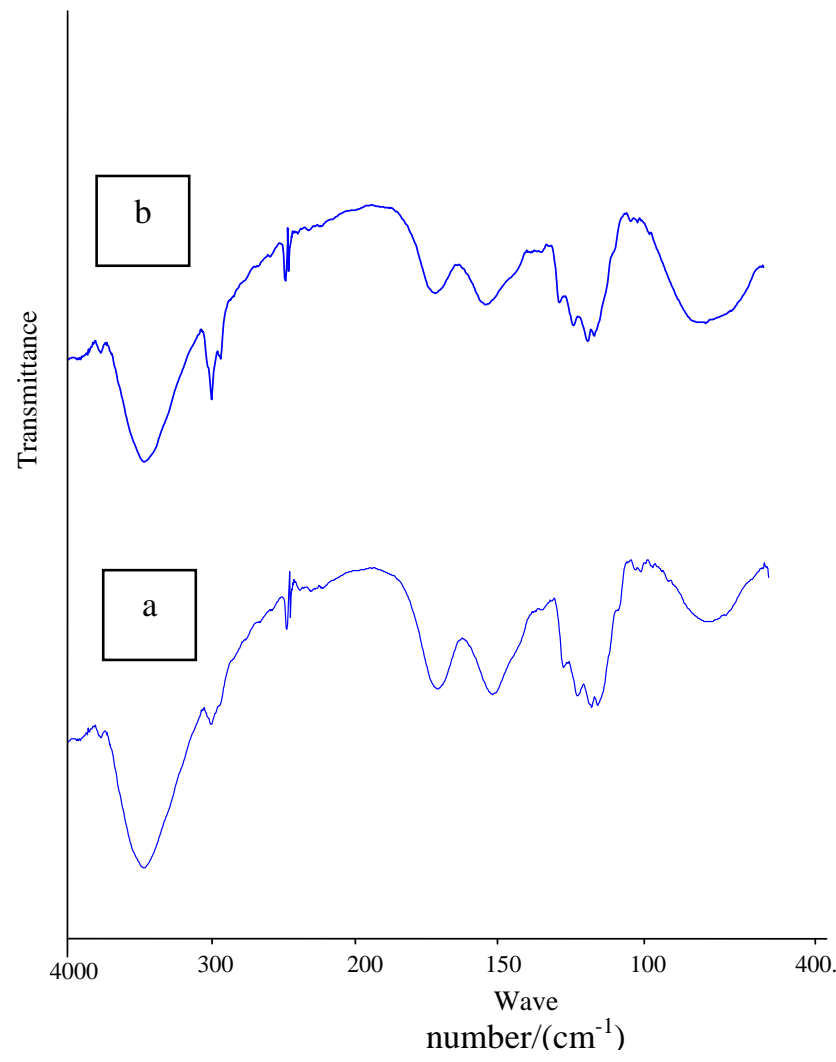

Figure 1. FT-IR spectra of rapeseed straw before and after pretreatment by P. Chrysosporium: (a) Before pretreatment, (b) On the 15th day of pretreatment.

\section{XRD anlysis}

The compounds of lignocellulosic biomasses are mainly cellulose, hemicellulose, and lignin, with Cellulose surrounded by lignin and hemicelluloses [12]. Hemicellulose and lignin are considered to be amorphous components, while cellulose is considered to be the crystalline component[14]. Due to the impossibility of complete separation of cellulose from other components of the fibers, the direct measurements of cellulose crystallinity in biomass are not possible[24]. At the present time, the measurement of crystallinity index by X Ray is the best choice to estimate the effectiveness of pretreatment in the crystallinity of biomass[25]. The intensities of the amorphous and crystalline regions were measured at $2 \theta$ equal to $18^{\circ}$ and $2 \theta$ equal to $22^{\circ}$ and $23^{\circ}$, respectively. Table 2 shows the crystallinity index for untreated and pretreated rapeseed straw with P. Chrysosporium. As shown in Table 2, the crystallinity index increased during pretreatment time so that after 15 days the amount of crystallinity index reaches $39.47 \%$ whereas its amount was $33.17 \%$ in un treated rapeseed straw. An increase in crystallinity index might be caused by degradation modification of hemicellulose and lignin, as reported in previous studies [14]. Therefore the 
crystallinity index increase in pretreated samples suggested that cellulose became more exposed after fungal pretreatment. This subject has been mentioned in some reports [14, 23].

Table 2. Crystallinity index of untreated and fungal-treated rapeseed straw by $\mathrm{P}$. Chrysosporium after 5, 10 and 15 days.

\begin{tabular}{lccc}
\hline \multirow{2}{*}{ Samples } & \multicolumn{3}{c}{$\operatorname{CrI}(\%)$} \\
\cline { 2 - 4 } & $5 \mathrm{~d}$ & $10 \mathrm{~d}$ & $15 \mathrm{~d}$ \\
\hline Untreated & 33.17 & 33.17 & 33.17 \\
Fungal treated & 34.23 & 37.15 & 39.47 \\
\hline
\end{tabular}

\section{Enzymatic hydrolysis rapeseed straw}

To evaluate the effect of pretreatment with P.Chrysosporium on the enzymatic hydrolysis of pretreated rapeseed straw, we determined hydrolysis ratio after enzymatic hydrolysis for 0-56 hours (Figure 2). As it is seen, untreated rapeseed straw was more resistant to enzymatic hydrolysis, producing only $2.2 \%$ hydrolysis ratio after 56 hours of hydrolysis. The hydrolysis ratio increased with the pretreatment time. The highest amounts of hydrolysis ratio of the rapeseed straws pretreated for 5 days, 10 days, and for 15 days reached about $3.6 \%, 4.8 \%$, and $6.6 \%$, respectively. These results show that the enzymatic hydrolysis is significantly affected by the pretreatment time. As the pretreatment time increases, delignification and hemicellulose removal increase as well causing more availability of the enzyme to cellulose and consequently improvement in the digestibility of cellulose[14].

Equation (1) was used to characterize hydrolysis kinetics by regression analysis of the experimental data. As shown in Figure 2(dotted curve), a good agreement with the experimental results was obtained the regression curves. As it is shown in Table 3, biological pretreatment of rapeseed straw with P.Chrysosporium increased the initial hydrolysis rate $\mathrm{V}_{0}$ at 5 th days. After 5 days of pretreatment, the initial hydrolysis rate $\mathrm{V}_{0}$ increased 1.38 fold, but it decreased with increasing pretreatment time. However, the rate retardation constant $\mathrm{k}$ decreased after the pretreatment, so that after 15 days, $\mathrm{k}$ value decreased 4.4 fold, which indicated that fungal pretreatment slowed down the decline in hydrolysis rate during enzymatic hydrolysis. Yu et al.[11] have reported similar results.

\section{Conclusion}

The research shows that the enzymatic hydrolysis of the rapeseed straw was enhanced by the biological pretreatment with P. Chrysosporium. The X-ray analysis exhibited a higher crystallinity for the all pretreated samples compared with controls. However, the fungal pretreated sample showed the highest crystallinity after 15 days. It increased from $33.17 \%$ at untreated rapeseed straw, to $39.47 \%$ for a pretreated sample after 15 days. The lignin degradation by P.Chrysosporium was confirmed through FTIR spectroscopy. The FTIR results indicating the preferential nature of this white rot. Moreover, the pretreatment slowed down the decline in hydrolysis rate during enzymatic hydrolysis, so that after 15 days, k value decreased 4.4 fold.

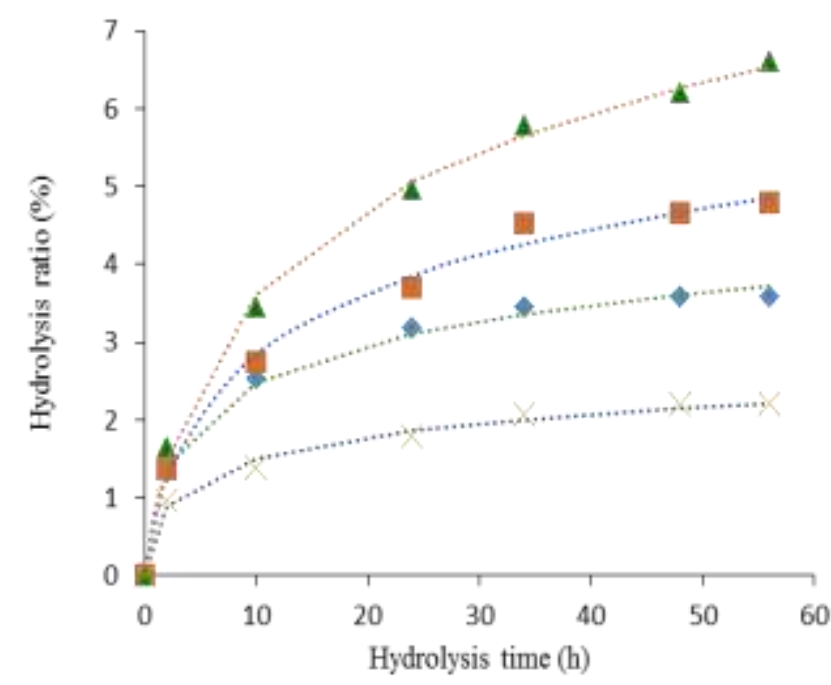

Figure 2. Time course of hydrolysis ratio (\%) during the hydrolysis of rapeseed straw(a) untreated $(\times)$ and (b) pretreated by p. Chrysosporium for 5 (४), 10 (ם) and $15(\mathbf{A})$ days.

Table 3. Kinetics parameters of enzymatic hydrolysis of untreated and fungal-treated rapeseed straw by $P$. Chrysosporium based on Eq. (1)

\begin{tabular}{lllll}
\hline $\begin{array}{c}\text { Pretreatment } \\
\text { time(day) }\end{array}$ & $\mathbf{v}_{\mathbf{0}}(\boldsymbol{\%} / \mathbf{h})$ & $\mathbf{k}$ & $\mathbf{R}^{\mathbf{2}}$ & $\mathbf{S S E}$ \\
\hline 0 & 1.530 & 2.415 & 0.991 & 0.036 \\
5 & 2.114 & 1.368 & 0.996 & 0.040 \\
10 & 1.133 & 0.817 & 0.994 & 0.114 \\
15 & 1.136 & 0.547 & 0.997 & 0.095 \\
\hline
\end{tabular}

\section{References}

[1] https: \lfaostat3.fao.org.

[2] Lu X, Zhang Y, Angelidaki I. Optimization of H2SO4catalyzed hydrothermal pretreatment of rapeseed straw for bioconversion to ethanol: Focusing on pretreatment at high solids content. Bioresource Technol 2009;100:3048-53.

[3] Kumar AG, Sekaran G, Krishnamoorthy S. Solid state fermentation of Achras zapota lignocellulose by Phanerochaete chrysosporium. Bioresource Technol 2006;97:1521-8.

[4] Zeng J, Singh D, Chen S. Biological pretreatment of wheat straw by Phanerochaete chrysosporium supplemented with inorganic salts. Bioresource Technol 2011;102:320614.

[5] Geddes CC, Peterson JJ, Roslander C, Zacchi G, Mullinnix MT, Shanmugam KT, et al. Optimizing the saccharification of sugar cane bagasse using dilute phosphoric acid followed by fungal cellulases. Bioresource Technol 2010;101(6):1851-7. 
[6] Margeot A, Hahn-Hagerdal B, Edlund M, Slade R, Monot F. New improvements for lignocellulosic ethanol. Curr Opin Biotech 2009;20(3):372-80.

[7] Li S, Li J, Hu X, Li M, Yan Z, Li S, et al. Study on enzymatic saccharification of Suaeda salsa as a new potential feedstock for bio-ethanol production. J Taiwan Inst Chem E 2013;44(6):904-10.

[8] Yamashita Y, Shono M, Sasaki C, Nakamura Y. Alkaline peroxide pretreatment for efficient enzymatic saccharification of bamboo. Carbohyd Polym 2010;79(4):914-20.

[9] Li X, Kim TH, Nghiem NP. Bioethanol production from corn stover using aqueous ammonia pretreatment and twophase simultaneous saccharification and fermentation (TPSSF). Bioresource Technol 2010;101(15):5910-6.

[10] Singh D, Chen S. The white-rot fungus Phanerochaete chrysosporium: conditions for the production of lignindegrading enzymes. Appl Microbiol Biot 2008;81(3):399417.

[11] Yu H, Guo G, Zhang X, Yan K, Xu C. The effect of biological pretreatment with the selective white-rot fungus Echinodontium taxodii on enzymatic hydrolysis of softwoods and hardwoods. Bioresource Technol 2009;100(21):5170-5.

[12] Sun Y, Cheng J. Hydrolysis of lignocellulosic materials for ethanol production: a review. Bioresource Technol 2002;83(1):1-11.

[13] Camarero S, Martinez MJM, Martinez AT. Understanding lignin biodegradation for the improved utilization of plant biomass in modern biorefineries. Biofuel Bioprod Bior 2014;8:615-25.

[14] Nazarpour F, Abdullah DK, Abdullah N, Zamiri R. Evaluation of Biological Pretreatment of Rubberwood with White Rot Fungi for Enzymatic Hydrolysis. Materials 2013;6:2059-73.

[15] Shrestha P, Rasmussen M, Khanal SK, Ometto III AP, Vanleeuwen JH. Solid-Substrate Fermentation of Corn Fiber by Phanerochaete chrysosporium and Subsequent Fermentation of Hydrolysate into Ethanol. J Agr Food Chem 2008;56:3918-24.

[16] Sedighi M, Karimi A, Vahabzadeh F. Involvement of ligninolytic enzymes of Phanerochaete chrysosporium in treating the textile effluent containing Astrazon Red FBL in a packed-bed bioreactor. J Hazard Mater 2009;169(13):88-93.

[17] Miller GL. Use of Dinitrosalicylic Acid Reagent for Determination of Reducing Sugar. Anal Chem 1959;31(3):426-8.

[18] Van Soest PJ. Use of detergents in the analysis of fibrous feeds II: a rapid method for the determination of fibre and lignin. J Assoc Agric Chem 1963;46:829-35.

[19] Segal L, Creely J, Martin A, Conrad C. An empirical method for estimating the degree of crystallinity of native cellulose using the $\mathrm{x}$-ray diffractometer. Text Res J 1959;29:786-94.

[20] Ohmine K, Ooshima H, Harano Y. Kinetic study on enzymatic hydrolysis of cellulose by cellulase from Trichoderma viride. . Biotechnol Bioeng 1983;25:2041-53.

[21] Ghasemzadeh R, Hamed Mosavian MT, Karimi A. Fungal Pretreatment of rapeseed straw by solid-state fermentation of Phanerochaete Chrysosporium to produce reducing sugars. Int J Bio Phar All Sci 2015;4(8):5711-21.
[22] Deswal D, Gupta R, Nandal P, Kuhad RC. Fungal pretreatment improves amenability of lignocellulosic material for its saccharification to sugars. Carbohyd Polym 2014;99(0):264-9.

[23] Zhang S, Jiang M, Zhou Z, Zhao M, Li Y. Selective removal of lignin in steam-exploded rice straw by Phanerochaete chrysosporium. Int Biodeter Biodegr 2012;75:89-95.

[24] Zhao XB, Wang L, Liu DH. Peracetic acid pretreatment of sugarcane bagasse for enzymatic hydrolysis: A continued work . J Chem Technol Biot 2008;83:950-6.

[25] Kumar R, Mago G, Balan V, Wyman CE. Physical and chemical characterizations of corn stover and poplar solids resulting from leading pretreatment technologies. Bioresource Technol 2009;100:3948-62. 